\title{
Cardiovascular risk estimation in Spanish HIV-infected patients: a multicenter cohort study
}

\author{
E Ferrer ${ }^{1}$, C Minguez ${ }^{2}$, A Mariño ${ }^{3}$, P Geijo ${ }^{4}$, F Brun ${ }^{5}$, J Sanz ${ }^{6}$, M Velasco ${ }^{7}$, \\ C Cortés ${ }^{8}$, A Castro $^{9}$, A Ortí10, ${ }^{10}$ Force $^{11}$, P Barrufet $^{11}$, C Villalonga $^{12}$ and \\ D Podzamczer*1
}

\begin{abstract}
Address: ${ }^{1}$ Hospital Universitari de Bellvitge, Barcelona, Spain, ${ }^{2}$ Hospital General de Castellon, Castellon, Spain, ${ }^{3}$ Hospital Arquitecto Marcide, Ferrol, Spain, ${ }^{4}$ Hospital Virgen de la Luz, Cuenca, Spain, ${ }^{5}$ Hospital Jerez de la Frontera, Jerez de la Frontera, Spain, ${ }^{6}$ Hospital de la Princesa, Madrid, Spain, ${ }^{7}$ Hospital Fundación Alcorcón, Madrid, Spain, ${ }^{8}$ Hospital de L'Hospitalet, Barcelona, Spain, ${ }^{9}$ Hospital Juan Canalejo, La Coruña, Spain, ${ }^{10}$ Hospital Verge de la Cinta, Tortosa, Spain, ${ }^{11}$ Hospital de Mataró, Mataró, Spain and ${ }^{12}$ Hospital Son Dureta, Palma de Mallorca, Spain

* Corresponding author
\end{abstract}

from Ninth International Congress on Drug Therapy in HIV Infection

Glasgow, UK. 9-13 November 2008

Published: 10 November 2008

Journal of the International AIDS Society 2008, I I (SuppI I):P92 doi:I0.I I86/I758-2652-II-SI-P92

This abstract is available from: http://www.jiasociety.org/content/I I/SI/P92

(c) 2008 Ferrer et al; licensee BioMed Central Ltd.

\section{Purpose of the study}

To assess estimated cardiovascular risk in a population of adult HIV-infected patients.

\section{Methods}

This is an ongoing, prospective, longitudinal, multicenter cohort study of estimated cardiovascular risk (eCVR). After obtaining informed consent, demographic characteristics, metabolic parameters, and clinical status, including CVR factors, of patients (pts) enrolled from February to August 2006 at 12 Spanish sites were recorded in a central database using an Access data set. eCVR was evaluated by the Framingham equation. For analysis purposes pts were grouped into: 1 ) low eCVR ( $<10 \%$ at 10 years); or 2 ) moderate/high eCVR (>10\%). Descriptive statistics were expressed as median (interquartile range) for quantitative variables and as percentages for qualitative variables. Logistic regression was used to identify the factors that might account for a higher eCVR. Baseline data are presented.

\section{Summary of results}

807 pts were included: $73 \%$ men, median age $41(18-83)$ years, $42 \%$ drug users, $26 \%$ AIDS, CD4 $465 / \mathrm{uL}, 51 \%$ undetectable viral load, 74\% taking HAART (51\% PI, 49\% NNRTI regimens), $64 \%$ smokers, $10 \%$ hypertension, $5 \%$ diabetes, 3.5\% coronary or cardiovascular disease (CVD). $81 \%$ pts had < 10 eCVR (Grp. 1) and 19\% $\geq 10$ eCVR (Grp. 2). Grp. 2 pts were more frequently men, older, non-drug users, smokers, diabetics, hypertensive, had CVD, lipid disturbances, greater waist circumference, greater BMI, undetectable viral load, and used more stavudine and indinavir. On univariate analysis, male sex (OR 8.51), coronary disease (5.77), CVD (3.87), diabetes (3.87), hypertension (3.66), smoking (1.96), age (1.16), lipid alterations (total cholesterol, HDL, LDL, Tryglicerides, noHDL and TC/HDL, 1.02 to 1.52 ), waist circumference (1.04), and BMI (1.04) were associated with increased eCVR, while detectable viral load was associated with a low eCVR (0.47). First or current antiretroviral drugs were not associated with increased eCVR. On multivariate analysis, male sex (OR 19.96), age (25.08), smoking (24.12), hypertension (5.41), and total cholesterol (1.04) remained significantly associated with increased eCVR while detectable viral load (0.38) and HDL (0.94) remained significantly associated with a low eCVR.

\section{Conclusion}

Traditional cardiovascular risk factors are associated with increased eCVR in our HIV population, and seem to have a stronger role than HAART and HIV infection. Lower eCVR in pts with detectable viral loads is probably related 
to younger age, lower waist circumference and systolic blood pressure, and a better lipid profile. Pts with higher eCVR may benefit from lipid-friendly ARV therapy, but interventions on life habits are crucial.

Publish with Bio Med Central and every scientist can read your work free of charge

"BioMed Central will be the most significant development for disseminating the results of biomedical research in our lifetime. " Sir Paul Nurse, Cancer Research UK

Your research papers will be:

- available free of charge to the entire biomedical community

- peer reviewed and published immediately upon acceptance

- cited in PubMed and archived on PubMed Central

- yours - you keep the copyright

Submit your manuscript here:

http://www.biomedcentral.com/info/publishing_adv.asp 